\title{
Transformation of Communities in Depopulation in Kanda District of Downtown Tokyo
}

\author{
TAIRA Atsushi \\ Faculty of Education, Kagawa University, Takamatsu 760-8522, Japan
}

\begin{abstract}
This study aims to explain the transformation of the community with the decrease of the population in Kanda district in the ward of Chiyoda, located in central Tokyo. In this study, the spatial unit of community is designated as the territory of choukai, and its higher unit is designated as the district of public elementary school. The decrease of the population, which began in the 1950s, has resulted in the increase of unused classrooms called "akikyoushitsu" in the public elementary schools located in and near the central business district of Tokyo. As a solution for that problem, a policy of changing public elementary schools into community centers through opening those facilities to the public has been undertaken. Chou$k a i$, which is a basic voluntary social association of urban residents, is also forced to shrink its size mainly due to out-migration of the population. They have been mostly young generations who have moved out the district. This out-migration has led to aging of residents and board members of choukai. The festival for ujigami, or tutelary deity, has been the main event of choukai and it has played an important role to maintain friendship among the residents. However, it is becoming more difficult to keep up the number of people needed to hold the festival. With transformation of resident structure and associations, the landscape of the district is also changing mainly because of rebuilding and remodeling. Many cases of rebuilding from one-story shop-houses into multi-story commercial buildings on an individual basis have been observed in Kanda district. It is estimated that the local community, which has been based on choukai, would be changed into a part of a much broader association consisting of united-choukai and other voluntary associations, and that the public elementary school could become a base of activities of those organizations as a community center.
\end{abstract}

Key words: community, social organization, public school, Tokyo

\section{Introduction}

This study aims to explain transformation of community with decrease of the population in Kanda district in the ward of Chiyoda, which is a part of the central business district of Tokyo. So far, sociology has led the field of study about social structure and organizations in the city. In Japan, the study of chounai-kai (voluntary association of residents based on the unit of neighborhood) has been the major theme. Fujita (1980) has explored the social characteristics of Japanese cities through chounai-kai studies and has argued that Japanese cities have been segmented into small spatial units by the central government and that the residents there have been the object of administration rather than the subject of local politics. The study of chounai-kai and that of community in urban areas include Yamamoto (1977), Kurata (1980), and Kashiwabara (1980). Yamamoto has surveyed depopulation processes in three wards (Higashi, Kita, and Minami), which make up the central business district of Osaka, and has pointed out the importance of introducing business entities (firms and individual enterprises) actively into chounai-kai activities now when they remain only in name. Kurata has referred to the transformation of the residential community due to its depopulation in a case study of the ward of Minami and Higashi, Osaka. Kurata has argued that although the residents there are still attached to their neighborhoods, the depopulation has made it difficult to keep up the number of persons needed to maintain the community organization, and that the activities of chounai-kai are becoming stagnant. Also, Kurata has claimed that the paucity of facilities for community activity has been a factor in the 
depression of community activities, and has pointed out the importance of activation of the residential community based on the local schools through opening them to local people. Kashiwabara has examined a case in which the local administration set up a new association to be the nucleus of community activities which have been becoming lirely using the facilities of the local public elementary schools. Kashiwabara has suggested that the elementary school district would be the appropriate unit for designating the spatial boundary of residential community.

In human geography, many studies of downtown have been conducted since the pioneer research by Murphy and Vance (1954). These studies have examined downtown as the central business and commercial district or the center of spatial urban structure. One of the characteristics of downtown is the unbalance of the daytime and nighttime population. There are, however, few studies which have considered downtown as residential space, and which have analyzed the characteristics of its residents and those of social organizations. Thus it is evident that previous studies have paid attention mostly to the daytime aspect of downtown. In this context, Kagawa's recent research (1984, 1988) is of importance in that these studies have examined the residential function in downtown. ${ }^{1}$

The fact that decrease of population is the most serious problem for downtown communities of the large cities is also referred to by a previous study of Yamamoto (1977). It is a recent trend that depopulation causes neighborhood activities, represented by chounai-kai, to be inactive and that it causes difficulty in maintaining cultural events represented by local religious festivals. At the same time, public educational institutions, which have no direct relation with various economic functions in downtown, also have been seriously affected by the depopulation and many public schools have been forced to merge or close down. These problems are also common with to rural depopulated areas.

The previous studies on urban educational institutions include Thomas and Robson (1984) and Bondi (1987). These studies have analyzed the decline of the functions of public elementary and junior-high schools in Manchester, the United Kingdom. Also, there is a study by Nishida (1986), who has examined the closure of elementary and junior-high schools in rural areas in western Japan and the changes in activities of residents. However, there is still a paucity of geographical studies from the point of educational aspects.

In this study, basic local community is defined as the whole body composed by residents and business organizations in a neighborhood based on the spatial unit of chouchou. And the district of a public elementary school is considered as a higher unit of community. Through the analysis of influences of depopulation on public educational institutions, transformation of community will be argued. The reason for considering chouchou as the basic unit of community is the fact that voluntary organizations of residents, called chounai-kai, chou-kai or jichi$k a i$, have been established on the spatial unit of chouchou. In this study, the word meaning voluntary association of residents, choukai, will be employed because that term is used in the study area. Also, the reason for considering the elementary school district as the higher unit of community is that the public elementary school is the most common numerous and countrywide institution among the public institutions for residents, and also that the public elementary school has been equipped with enough facilities to be the center for various activities of residents in its school district. Then, the transformation of the district, including the change in landscape, will be examined. The previous studies in sociology on transformation of local societies have mainly dealt with the characteristics of residents. But considering that the residential facility is the base of space for everyday life, it is assumed that the differences in residential facility may result in frequency and density of communications and relations with neighbors. Remodeling and rebuilding of residential facilities would lead to landscape changes. Thus, in this study, this kind of observable change will also be considered in the context of transformation of community.

The following section will deal with dynam- 


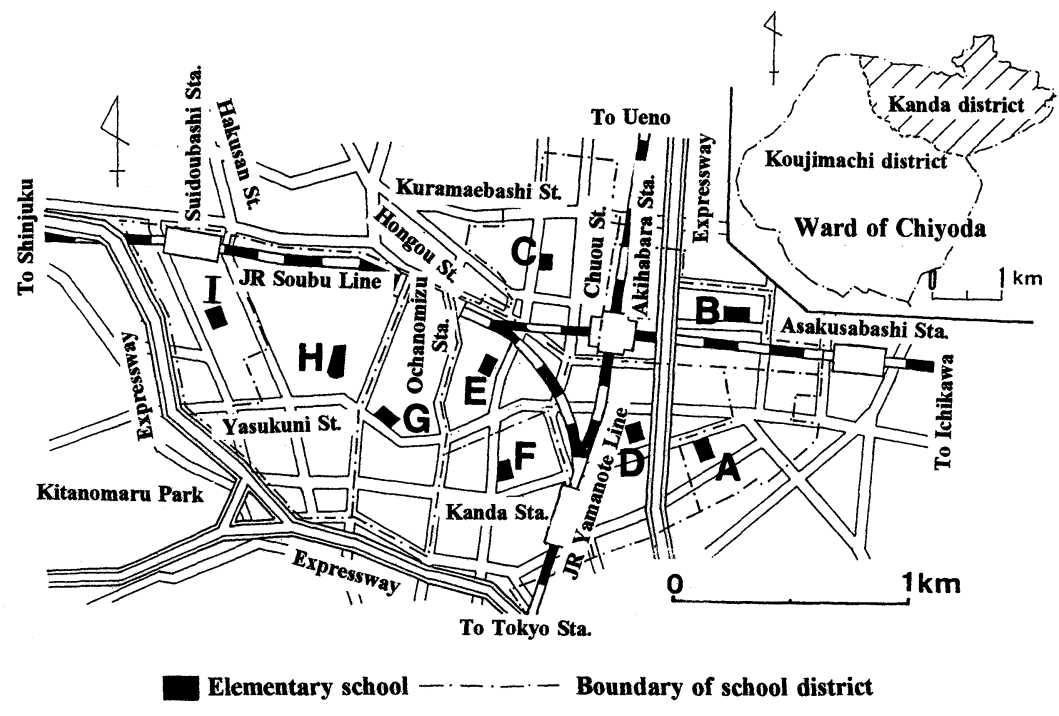

Name of school:

A: Imagawa, B: Sakuma, C: Hourin, D: Chizakura, E: Awaji

F: Kanda, G: Ogawa, H: Kinka, I: Nishikanda

Figure 1. Study area.

ics of the local population through cohort analysis. In the third section, effects of depopulation on the public elementary schools and the responses of those schools will be argued based on data about facility utilization of public schools and about the changing number of pupils owned by the local board of Education and the schools themselves. The forth section will examine transformation of the choukai community. Activities of residents' association, change in the number of residents, characteristics of residents, types of residences and change of landscape through remodeling and rebuilding will be examined. The data sources about the residents are the registration records of residents and the directory of chou-kai, supplemented by interviews of residents by the author. Changes of landscape were mapped out at the scale of chou-kai by analyzing jutakuchizu, or residence maps, and other public maps. Field observation was also conducted in late 1988. Owners of the buildings were clarified by interview research.

The case study area is Kanda district in the ward of Chiyoda, Tokyo (Figure 1). The ward of Chiyoda, which is dominated by business and commercial functions except for the west-

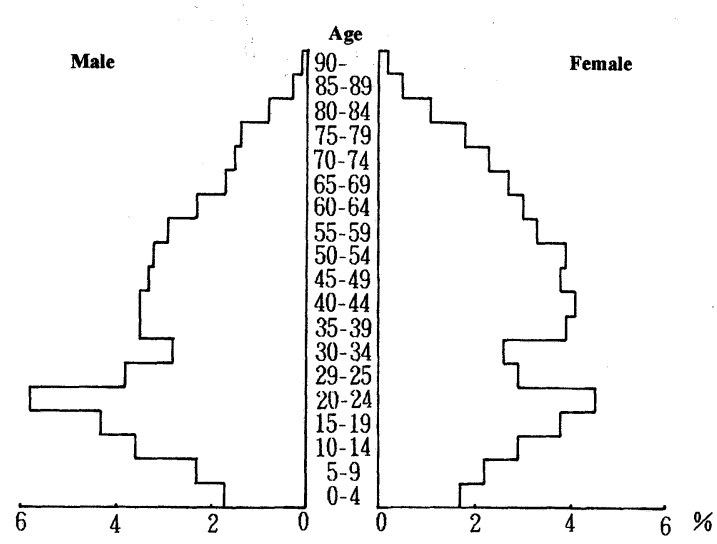

Figure 2. Population pyramid of Chiyoda ward, 1988.

Source: Unpublished document of the ward of Chiyoda.

side of the Imperial Palace, shows a very clear difference between the daytime and nighttime population. The area of Ote-machi to Nagatacho becomes almost a no-man's-land at night. The current Chiyoda ward was formed when the ward of Kanda and Kojimachi merged in 1947. The area of the former Kanda ward corresponds to the current four subareas administered by the branches of the ward Chiyoda 


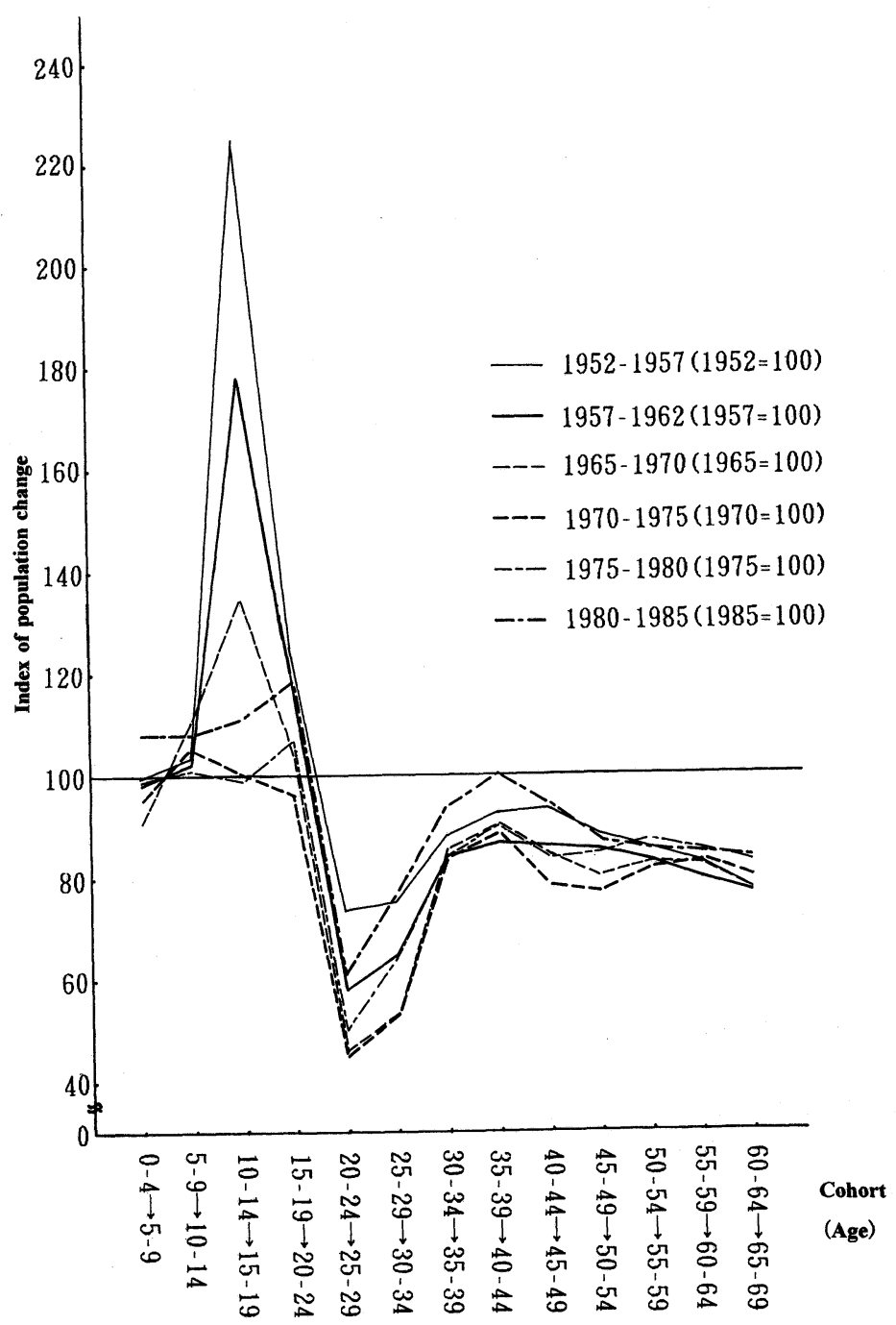

Figure 3. Population change by cohort in Chiyoda ward, 1952-1962 and 1965-1985. Source: Unpublished document of the ward of Chiyoda.

Jimbo-cho, Kanda-kouen, Izumibashi, and Banseibashi; the area of the former ward of Kojimachi corresponds to the current two subareas of the ward of Chiyoda: Fujimicho and Bancho. In this study, the former area will be called Kanda district and the latter Kojimachi district. Kanda district is a downtown area dominated by business and commercial activities, while Kojimachi district is mainly occupied by residences. As of January 1, 1988, Kanda district had a population of 26,512 and Kojimachi district of 25,272. A hypothesis of the study is that traditional downtown community might become disorganized along with the decrease of the population.

\section{Process of Depopulation}

The population of the ward of Chiyoda peaked at 122,000 in 1955 and then it began to decrease to 62,000 in 1975 . On the other hand, the daytime population kept rising after World War II to 350,000 in 1950 and to 930,000 in 1975.

Figure 2 shows the population pyramid of the ward of Chiyoda as of January 1, 1988. Its graph has a spindle-like shape with a projection of a cohort in the age of early 20s. Also, the 
share of aged people is high: the population of 65 years old and over occupies 14.3 percent of the total. If calculated only in Kanda district, the percentage is up to 18 percent.

Next, cohort analysis was performed in order to grasp the change of population structure based on age cohort. Figure 3 presents the population change by cohort in the ward of Chiyoda from 1952 to 1962 and from 1965 to 1985. The horizontal axis is age cohorts and the vertical one is the index of population change. The figure shows that the population increase of low teens was strong from 1952 to 1957 when the population of the ward of Chiyoda reached its peak. It is estimated that one reason was the return of students from evacuated places after World War II and inflow of young workers. The index of population change over this age cohort shrank rapidly with a strong population decrease in the age cohort of the early twenties. The population decrease was accentuated from 1957 to 1962 . A major reason for that was the slowdown of increase in the age cohort of the teens, which quickened the entire population decrease with that of the twenties. The changing situation from 1965 to 1975 was as follows: the pace of population increase in the low teens slowed down and ultimately, its increase and decrease balanced. The population of the ward of Chiyoda was down 34 percent from 93,000 to 61,000 in this period and a major factor for that was also the rapid slowdown of a population increase in the low teens. Another reason was a decrease of the population in the twenties. The population in the low twenties showed a 50 percent decrease both in the early and late 1970s.

The population decrease of the ward of Chiyoda slowed down after 1975. Comparing the period from 1965 to 1975 and that from 1975 to 1985 , it is clear that the age cohort in the upper teens, which turned into reduction from 1970 to 1975, resumed increasing and that the reduction pace of the age cohort in the twenties slowed down. Thus, it is possible to estimate that the population change in those cohorts was the major reason for the sluggish trend of the entire population decrease. However, since the population reduction in the twenties did not halt and has led to the decrease of the childbirth

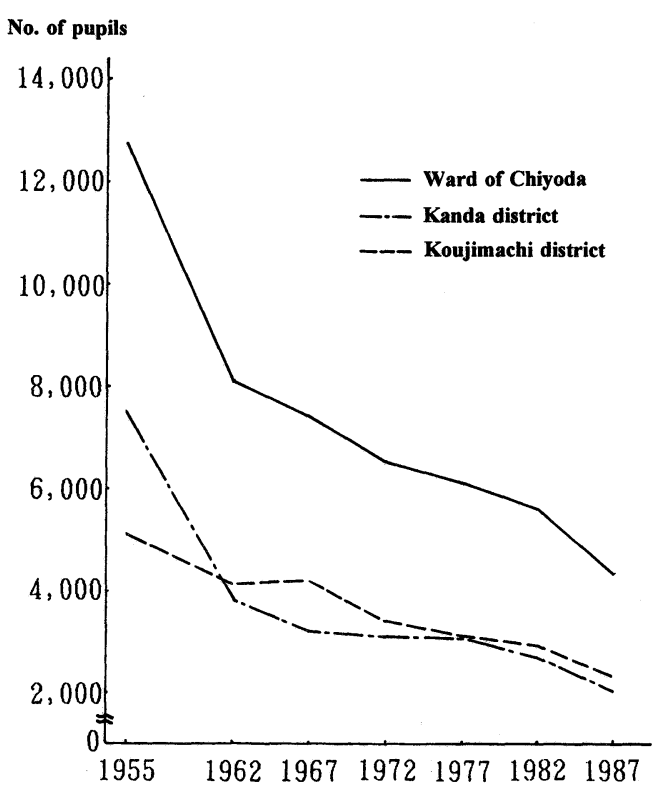

Figure 4. Number of pupils in the public elementary schools of Chiyoda ward, 1955-1987.

Source: Unpublished document of the Board of School of the ward of Chiyoda.

population, it is assumed that the reduction of the young population will continue in the future.

\section{Declining School Enrollment and Multiple Use of School Facilities}

The number of pupils kept decreasing along with that of the population. Figure 4 shows the change in the number of pupils in the ward of Chiyoda, Kanda and Kojimachi districts after 1955. The number of pupils in the ward of Chiyoda diminished dramatically from 12,700 in 1955 to 8,029 in 1962 , a 36.8 percent reduction. This reduction was due to that in Kanda district.

Figure 5 illustrates the enrollment of pupils of each public elementary school and their shares of lower graders (the first to third graders) and upper graders (the fourth to sixth graders). All public elementary schools in Kanda district were small in scale ${ }^{2}$ : the largest school $\mathrm{H}$ had only 386 pupils in 1988, and the smallest school $\mathrm{E}$ had 130 pupils with only 18 first graders. Since the shares of lower graders in the entire school enrollment of each elementary 


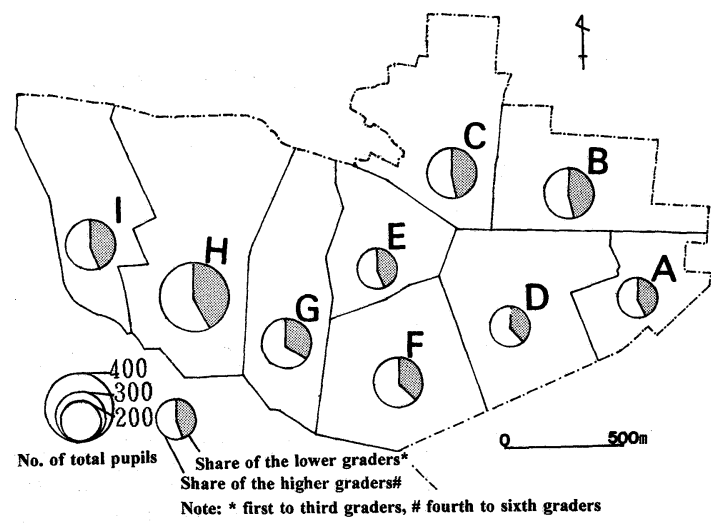

Figure 5. Number and composition of pupils in elementary schools of Kanda district, 1987.

Source: Unpublished document of the Board of School of the ward of Chiyoda.

school were almost the same, it is possible to assume that the decease in the number of pupils would continue.

On the other hand, since the number of pupils of elementary schools in the ward of Chiyoda included a significant number of pupils commuting from other wards and cities (it is called kuiki-gai tsuugaku), that number did not match that of pupils residing in the ward. Those commuters from outside the ward were admitted by the school board only when the pupils had a direct relationship with the ward of Chiyoda such as having parents who had gone to the same school or who were working in the ward. It is estimated that about 30 percent of the pupils in the ward of Chiyoda came from outside the ward. Figure 6 shows a geographical distribution of place of residence of pupils residing outside the ward of Chiyoda and attending school W located in Kanda district. The share of pupils coming from outside its school district was 43.4 percent of the total: 8.6 percent of the total coming from other school districts inside the ward of Chiyoda and 34.8 percent from outside the ward. Seventy percent of pupils commuting from outside the ward came from the wards of Katsushika, Edogawa, and Koutou located in the east side of Tokyo. This distribution pattern shows a tendency of directivity of out-migration of a generation who has school age children.

The board of a school in the ward of Chiyoda established a committee for arguing conditions of school education ${ }^{3}$ in 1987 to cope with problems caused by the decrease in number of pupils. This committee assumed that the number of pupils would continue to decrease at the pace of four to eight percent annually, reaching 3,200 in 1992 , a 22 percent reduction compared to the number in 1988 , and that six elementary schools out of 14 would have only one class in each grade. In school education in Japan, one of the purposes is to assist growth of pupils and students through group activities. In order to fulfill this purpose, it would be needed to expand the scale of schools and the number of pupils through mergers of the existing elementary schools.

The decrease of pupils generated a new problem of the increasing number of unused classrooms and their effective utilization. An unused classroom called aki-kyoushitsu, is one which has not been used as the space for a home base of any grade. Based on a document by the school board of the Tokyo Metropolitan Government, there were 5,700 unused classrooms out of 20,600 total classrooms in the entire public elementary schools, 38.3 percent of the total, as of May 1, 1987 (Table 1). Unused classrooms have been firstly diverted to classrooms for special subjects such as music and arts, which had been in short supply, secondly to those for special activities such as pupils' council activities, and thirdly to rooms for other purposes such as meeting rooms. Although it is not clear how many unused classrooms have been opened to social education and community activities, the high rate of unused classrooms indicates insufficient diversion of the classrooms so far. ${ }^{4}$

The first point of issue for opening facilities of public schools is supervision and responsibility for using them. In other words, the premise for effective use of school facilities is establishing a system in which the local community organization manages the facility control and takes responsibility based on the rules. Ultimately, it is expected to make public schools into community facilities by initiative of local residents for multi purposes such as for lifelong study, sports and cultural activities on weekends and in after-school hours. 


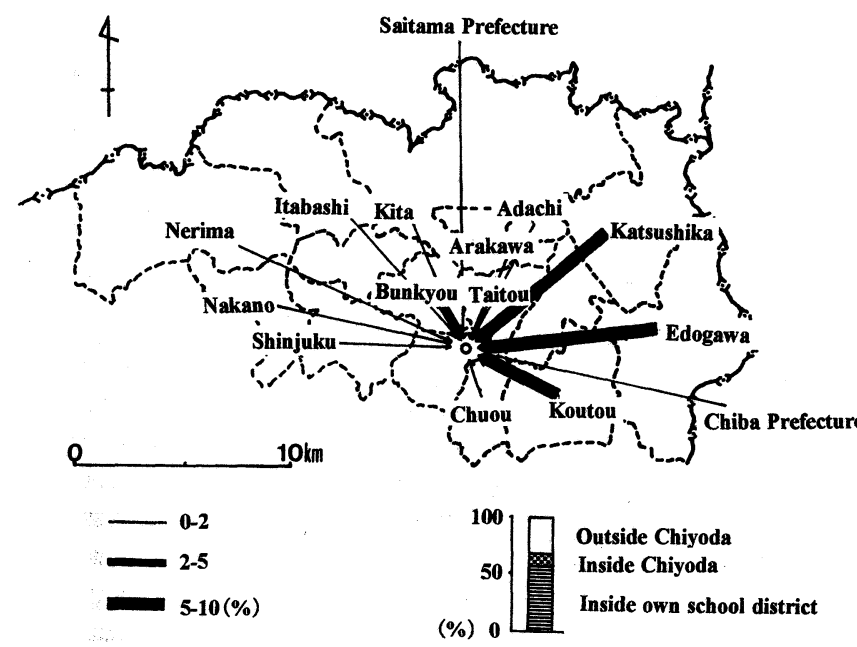

Figure 6. Places of residency of the pupils of a sample elementary school, 1988. Source: Directory of a sample school.

Table 1. Unoccupied classrooms in public elementary and junior-high schools in Tokyo, 1988

\begin{tabular}{ccccc}
\hline Type of school & Admitted classrooms & Present classrooms & Unoccupied classrooms & \% unoccupied \\
\hline Elementary & 20,600 & 14,900 & 5,700 & 27.7 \\
Junior-high & 8,700 & 7,400 & 1,300 & 14.9 \\
\hline Total & 29,300 & 22,300 & 7,000 & 23.9 \\
\hline
\end{tabular}

Source: Unpublished document of Division of Social Education, Board of School of the Tokyo Metropolitan Government.

Sakuma public elementary school was transformed into a multi-purpose facility called "Chiyoda Park-side Plaza" at the time of its rebuilding in September, 1987. This project was one of the main projects of the long-term general plan of the ward of Chiyoda for making a city which has a balance of vigor and tranquillity. The building houses five institutions: the park side plaza as community center, Sakuma elementary school and kindergarten, the Institute of Education, and Izumi nursery school. A principle is to regard the elementary school as the core of the local community. Its swimming pool and rooms for special subjects such as music are open to the public except when they are used for ordinary school education. The building has a number of meeting rooms, a multipurpose hall, and a library room, and the Plaza plays a pivotal role as a study space for all generations.

\section{Transformation of Community Based on Choukai}

This section is devoted to explain the transformation of community based on choukai. The definition of community varies in disciplines and its spatial unit is also varies according to the researcher. McIver (1917) defined community as the whole entity of residents in a locality which was differentiated naturally from others by residing and belonging. In Japanese cities, it is evident that the neighborhood called chouchou is the basic spatial unit of everyday life by the fact of the establishing principle of neighborhood associations called chounai-kai or $j i c h i-k a i$. On the other hand, in sociology, it has been also claimed that the public elementary school district should be the unit of community. The reason for that is, as mentioned before, that public schools are located throughout the country and that they are equipped with enough facilities to be the core of residents' activites. 
This study considers the spatial unit of choukai (a term used in Kanda district) as the basic unit of community, and choukai as the nucleus of resident's activities. Generally, although the spatial boundary of choukai corresponds to that of chouchou, there are some cases in which plural choukais exist inside a chouchou and in which the current choukai is based on the former chouchou before merger.

\section{Activities of choukai and community}

The activities of choukai, which have been the main community activities, include those for promoting friendship among residents, those in cooperation with the local administration, voluntary social activities, those for getting residents' opinions together, and those for conveying residents' demands to the local government. The activities for promoting friendship among members consist of condolences and congratulations, festivals, the new year party, tour programs and so on. Cooperative activities for the local administration are sanitation maintainance, beautification of neighborhoods, protection drives against calamities and crimes, and distribution service of public relation magazines. Voluntary activities include charity, environmental maintenance, and cooperation in school activities.

Three sample neighborhoods in Kanda district were chosen for detailed analysis: North Jinbo-cho 1-chome, North Ogawa-machi 3chome, and former Tsukasa-cho 1-chome. The landscape there consists of traditional low-rise shop-houses and high-rise commercial buildings and those neighborhoods are located adjacent to Otemachi and Surugadai area, which is a part of the central business district of Tokyo. In North Jinbo-cho 1-chome, low-rise buildings occupied a signficant part, and in contrast, former Tsukasa-cho 1-chome was dominated by high-rise buildings. Ogawa-machi was in the middle (Figure 7).

The northeast part of North Jinbo-cho 1chome ${ }^{5}$ is neighboring the north part of Ogawacho 3-chome. The choukai of North Jinbocho 1chome was established in 1952. The number of members was 473 as of 1988: 157 of them were resident members and almost half of all the members were corporate members. The corpo- rate members pay membership fees and cooperate in choukai activities. At the time when individual members have been declining, the corporate members have played an important role in stabilizing the finacial basis of choukai. Although most individual members were selfemployed, it is difficult to distinguish clearly between them and corporate members in small business. Concerning the type of business of the choukai members, 42.8 percent were in the wholesale and retail sector, including restaurants occupying about half. Those in the manufcturing and service sector followed with a 22.5 percent share each. It is a local characteristic that 73 percent of the members in the manufacturing sector were engaged in the publishing and printing business.

In Jinbo-cho 1-chome, the significant population outflow, which has influenced the choukai activity, began in the 1980s. Figure 8 shows an inhabited area in North Jinbo-cho 1-chome in 1934,1972 , and 1988. In 1934, residents were found throughout the neighborhood at a high density. Although the population of Kanda disrict decreased sharply due to the bombardment during World War II, the area was reconstructed in a short period after the war. As mentioned before, the population of the ward of Chiyoda reached 125,000 , its peak, in 1955 . In 1872 when the ward population was down to 70,000 , Jinbocho 1-chome had about 240 households. From 1972 to 1988 , North Jinbo-cho 1chome lost about 50 households, 20 percent of the total.

The examples of activities of choukai have been those for mutual friendship among choukai members such as hatsumoude (visiting shinto shrine on January 1) to Misaki Shrine, a local shrine, which deifies ujigami (community god), shinnen-kai (new-year party), a party for freshmen of the local elementary school, and a festival for ujigami, and those for social purposes such as a drive for environmental protection and a blood donation campaign. The festival of Misaki Shrine, the largest activity of choukai of North Jinbo-cho 1-chome, has been held in early May every year. Generally, suborganizations of choukai have enforced those activities. Choukai of North Jinbo-cho 1-chome consisted of eleven sub-organizations such as 



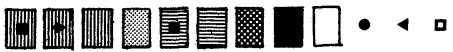

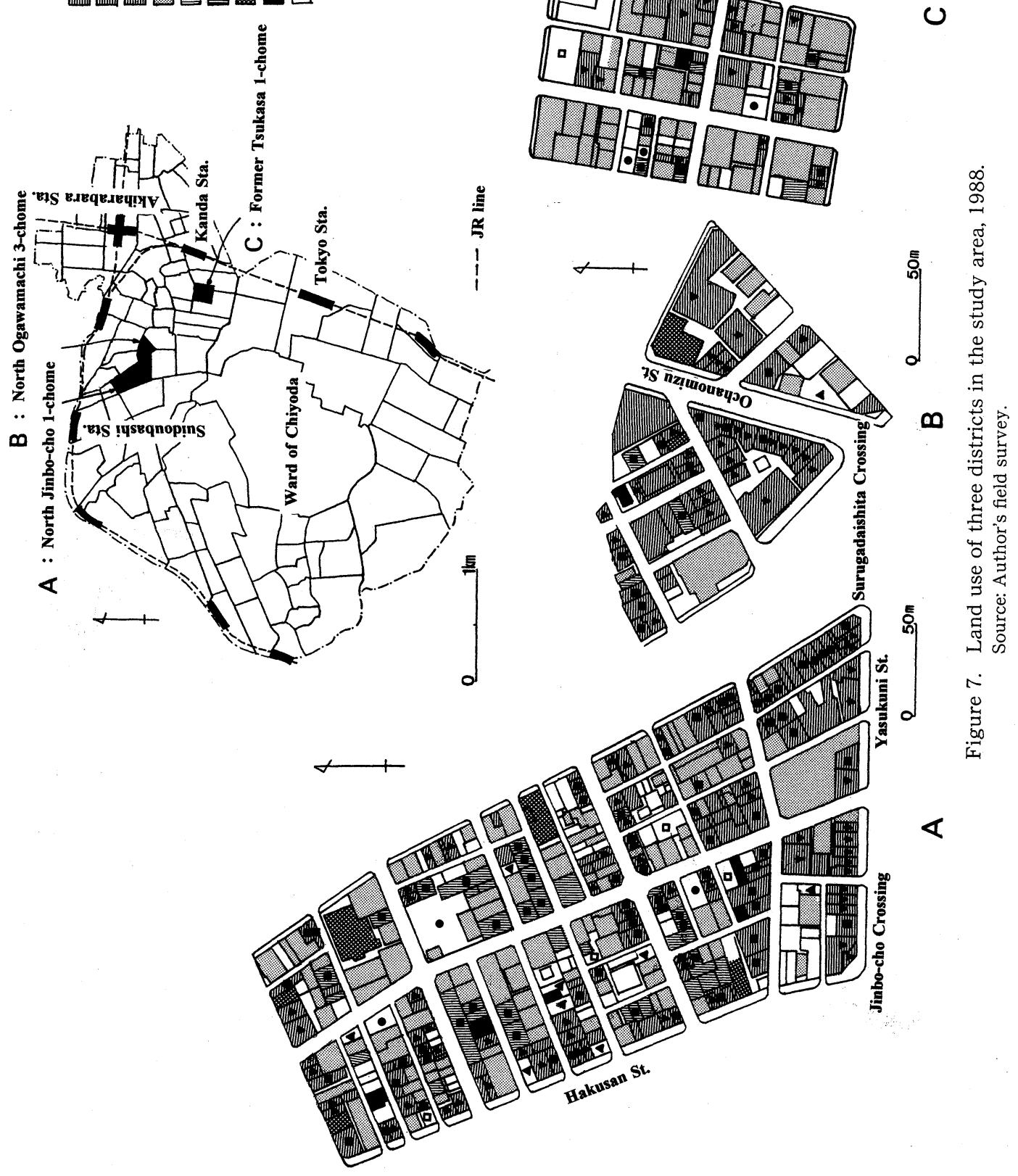






A : 1934

B : 1972

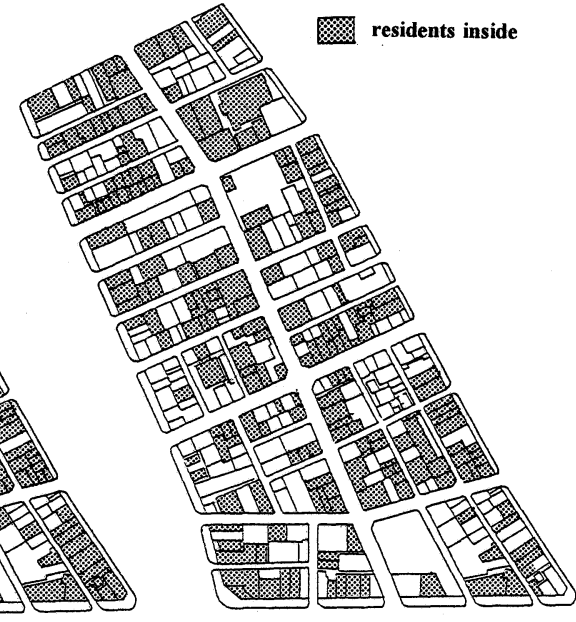

C : 1988

Figure 8. Inhabited area in North Jinbo-cho 1-chome, 1934, 1972, and 1988.

Source: Unpublished document of choukai, registration records of the residents in the ward of Chiyoda, residential maps, and author's field survey.

that for prevention of crime, women's association, youngmen's association and cultural association.

The choukai of Ogawa-machi 3-chome West was founded in 1955. Originally, Choukai of entire Ogawa-machi was composed of seven choukai before World War II: four of them were organized in the area north of Yasukuni Street and three in the area south of the street. As of 1988, the choukai of Ogawa-machi 3-chome West had 193 members: a third were individual members, outnumbered by corporate members. Most of the individual members were self-employed in the retail and manufacturing sectors, just as in the choukai of North Jinbo-cho 1chome and these self-employed members have been playing the major role in maintaining the choukai activities. Corporate members have payed the annual fees and sustained the financial bases of choukai. The type of business of members was almost the same as that of North Jinbo-cho 1-chome: 46.2 percent of them were engaged in the wholesale and retail sector, and 29.8 percent in the service sector. The choukai of Ogawa-machi 3-chome west has been enforcing many activities, performed by seven suborganizations.

The Tsukasa-ichi choukai has been covering Uchikanda 1-chome and a part of Uchikanda 2- chome. Originally, this area was divided into three sub-areas: Minamigawa-machi, Rousokumachi and Mikawa-cho 2-chome. In 1935 these three sub-areas were forged into Tsukasa 1chome, and in 1975 it was reorganized into Uchikanda under the new placename division enforcement. However, the choukai and its name have been maintained based on the former neighborhood division.

As of 1988, Tsukasa-ichi choukai had about 400 members: three-fourths of them were corporate members and the share of individual members was the smallest among three choukais. About 90 percent of individual members resided in the neighborhood and the rest were keeping their working places in the neighborhood, with their own residense outside the neighborhood. It is assumed that the high percentage of corporate members of Tsukasa-ichi choukai would be due to the location of the neighborhood, which is next to Otemachi, a cental business district of downtown Tokyo and its expansion.

The activities of Tsukasa-ichi choukai have been simplified mainly because of its small number of individual members. Here also, the festival for the local god has been the main activity of choukai. The small special building for the local god called shaden was constructed 


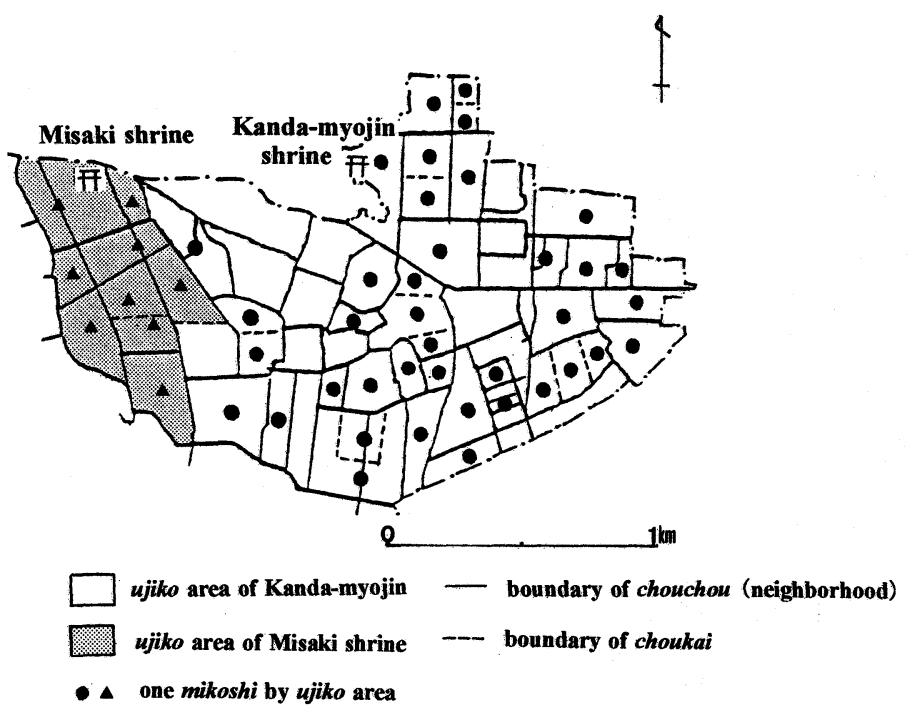

Figure 9. Area of surrounding Kanda-myojin and Misaki shrines, 1988. Source: Unpublished document of the shrines and author's field survey.

in around 1960 inside the land of Kanda-myojin shrine, the major Shinto shrine in Kanda district. Since the construction was completed in October that year, the festival for the local god came to be held in October afterward. Another festival for Taira-no Masakado, a head of the local samurai group in the Kanto region in the 10th century, has been organized every September by a number of choukais surrounding kubizuka (a tomb burying the head) of Taira-no Masakado. The coporate members have also been taking part in this festival. Every August, the choukai opens kodomo-en'nichi (traditional children's festival), setting up many attraction booths on Kanda-nishiguchi shopping street, aiming to let children experience the atomosphere of Japanese traditional festival. However, the decrease in number of pupils has been also experienced in this neighborhood. In 1988, the congratulation ceremony for the freshmen to the local elementary school was canceled due to the absence of freshmen.

It was mentioned before that the festival for the local god had been the pivotal one in the choukai activities. A reason for that is the fact that the choukai originated from the machigumi, or community organization, which was born in the mid-Edo period, and that the machigumi had a stong connention to ujigami. Generally, the branch of the main shirine had been set up in the neighborhood, and the festival for the local god had been held based on these neighborhoods. That kind of tradition was handed down up to the present without interruption.

Kanda district is divided into two areas of ujiko (worshipers of a shrine): the area of Kanda-myojin shrine and that of Misaki-jinja shrine. ${ }^{6}$ Following sections will explain the relationships between choukai and ujigami through analysis of each festival.

Oringinally, the festival of Kanda-myojin shrine ${ }^{7}$ had been held on May 15 . But considering the heavy trafic on the roads, it is currently held on the weekend just before May 15. The donation drive for the festival begins one month before. A week before the festival, omikijo (a booth serving special sake for the local god) opens in the neighborhood. The preparation for the festival is completed when the shinkan (priest of the shrine) enters the spirit of god into each mikoshi (portable shrine) of choukai in the evening of the day preceding the festival. On the Saturday, each mikoshi makes the rounds of its neighborhood, and on the Sunday, mikoshis gather together and stand in line at the designated place, and go to the Kanda-myojin shrine. This act is called rengoutogyo (united visiting to the shrine). In some cases, a mikoshi is maintained by two or three choukais together, if the scale of choukai is not 
large enough for keeping it by itself. Repair of mikosh $i$ is needed every two to three years and this is financed by donation from its choukai members.

Carrying a mikoshi requires about 200 people, if it is a small one, and about 400 people, if it is a large one, including assistants surrounding the mikoshi. Since around 1970, it became difficult to gather enough people to carry mikoshi by choukai itself and the choukai began to ask help from the previous residents and friends. Some choukais partly rely on assistance from outside, voluntary organizations which specialize in helping traditional festivals.

Although the date of the festival for Misaki shrine is May 8 every year, the festival itself has been held in the weekend just before that festival date, the same as the case of Kandamyojin shirine, considering trafic safety. The expenses for the festival have been also based on the donations from choukai members. Ujikoseinendan, the young adults association of worshipers of the shrine, prepare and execute the festival. On Friday, the day previous to the festival, they take out mikosh $i$ from its garage, which is called kuradashi of mikoshi, and shinkan enters the spirit into mikoshi. At the same time, omikisho is set up at the designated place in the community. The next day, mikoshis of each choukai line up and go to Misaki shrine in a row. On the Sunday the mikoshi of the shrine is handed out to the community and it goes around each choukai with its members. It needs about three hundred people. Figure 9 shows the distribution of mikoshi owned by choukai.

It takes time and requires cooperation among members of choukai in order to prepare and excute the festival. Also, it is a fact that the festival itself helps to strengthen partnership and to build trust among the choukai members. The activities of the voluntary associations, such as matsuri doukoukai mentioned before, which have been organizied beyond the boundaries of choukai, indirectly indicate an aspect of transformation of the traditional community. When it becomes difficult for choukai to carry out its functions by the members themselves, it needs some sort of organizations to assist choukai.
When the member's relationship in the choukai community is maintained as in the case of Kanda district, the community itself does not break down easily even under depopulation. It is often the case that the people who remain in the community try to execute activities of choukai together and to maintain its tradition. The reason for the birth of the voluntary association, which was organized beyond the choukai boundaries for assisting the festival, is that Kanda district has its potential. As of 1988, the complete halt of choukai activities was not observed, although the scale of those activities was forced to be small. However, maintaining these activities is estimated to be more difficult in the near future, if the decrease of residents, who have been main players of choukai, continues. In order to keep community activities, it would be necessary to change the framework of choukai and to move the center of activity from choukai to choukai-rengou, or united-choukai association. At the same time, it can also be considered that the public elementary school, which has enough facilities and which is located at the community scale, can play a role as the central place of activity of community as in the example shown before.

The smallness of the scale of choukai, mostly with a few hundred square meters, has made it possible for choukai to maintain activities based on the strong relationships among members. But, since the smallness itself causes the limited budget for activities, it is not easy to fulfill all desires of the residents. Thus, in order to make up for these shortcomings, the residents' side needs to organize activities based on the unitedchoukais, and the local administration side needs to set up public facilites. In the ward of Chiyoda, united-choukai association was organized in 1955 based on the spatial unit controled by a branch of the ward office. The main purposes have been information exchange among choukais, execution of cooperative activities, transferring desires and intentions of members of choukai to the local government and transferring of information to members from the local government. But actually, to date, unitedchoukai association has limited its function mainly to information exchange and have been to execute cooperative activities. 


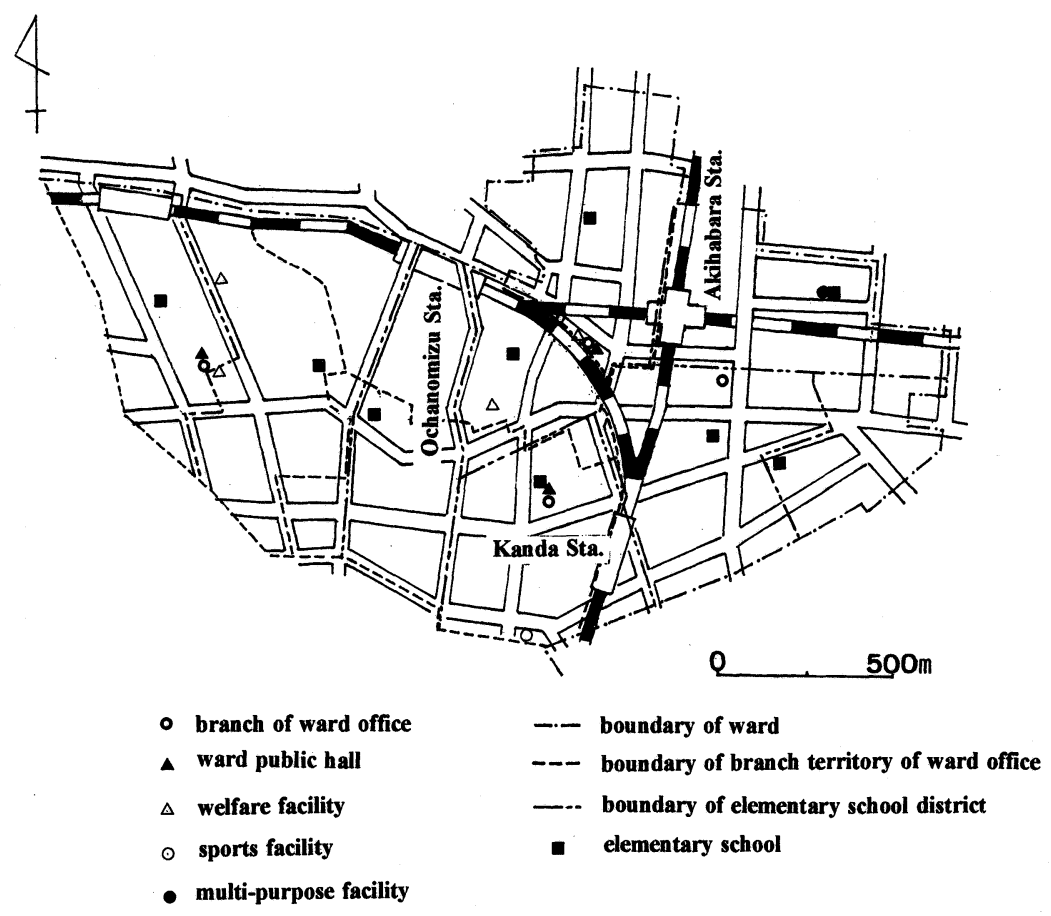

Figure 10. Distribution of public institutions in Kanda district, 1988. Source: Unpublished document of the ward of Chiyoda.

Figure 10 shows the distribution of public institutions as of 1988. The number of users of facilities has been stagnant. ${ }^{8}$ One of the reasons for that is the decrease of the population of the ward of Chiyoda. However, another reason would be that those facilities have mismatched residents' desires and tastes. According to a public opinion poll in the ward of Chiyoda in 1987, 38.1 percent of respondents wanted to have more sports facilities. Since it is very difficult for choukai, with its limited capacity, to construct such large and expensive facilities by itself, an active public policy by the local government would be required. In this sense, Chiyoda Parkside Plaza which houses a public elementary school, detailed in the previous section, is an epochal example of a facility which has the capacity to respond to residents' desires and to be a center of expanded-community beyond the boundary of traditional choukai.

\section{Transformation of landscape and residential structure}

Transformation of community stems from assembled internal changes. Residential space is important for individuals and families as nuclei of living space, as community space is for its people. Rebuilding and remodelling, including residential space, are observable changes. In this section, the author will focus on rebuilding in Kanda disrict and analyze its relation to the transformation of community. The distinctive landscape changes due to rebuilding have three main patterns. 1: using the ground floor as owner's shops or workshops, and leasing upper floors as rental shops and offices. In this case, the top floor is used either as residential space for the owner's family or as rental space. In the latter case, the owner resides outside the neighborhood. 2: using the whole building by the owner. In this case, also, the building can include or exclude residential space. 3 : changing plural individual shop-houses into one commercial building in cooperation.

Figure 11 shows the distribution of commercial buildings constucted individually and in cooperation by the residents in 1972 and 1988. In North Jimbo-cho 1-chome, in 1872, there were only 14 commercial buildings of this type, located along Yasukuni street and in its sur- 


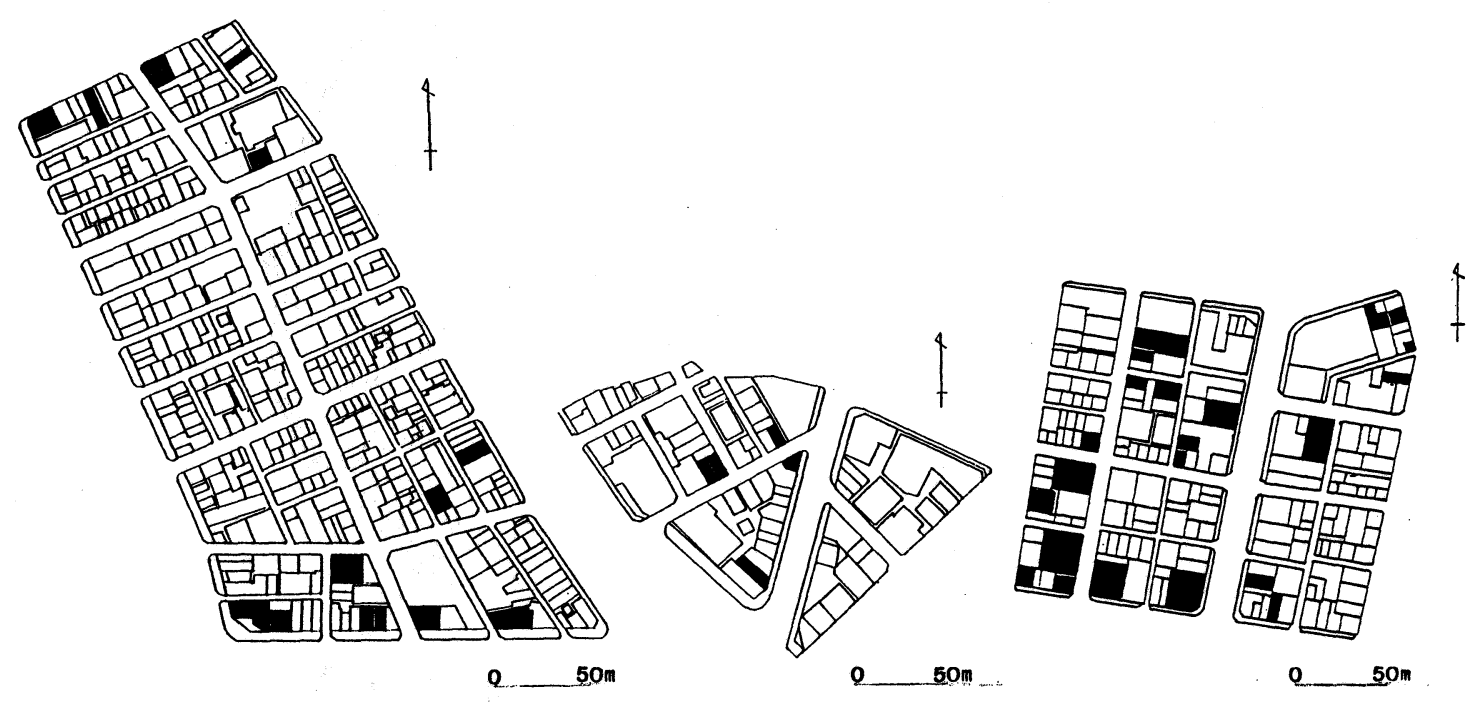

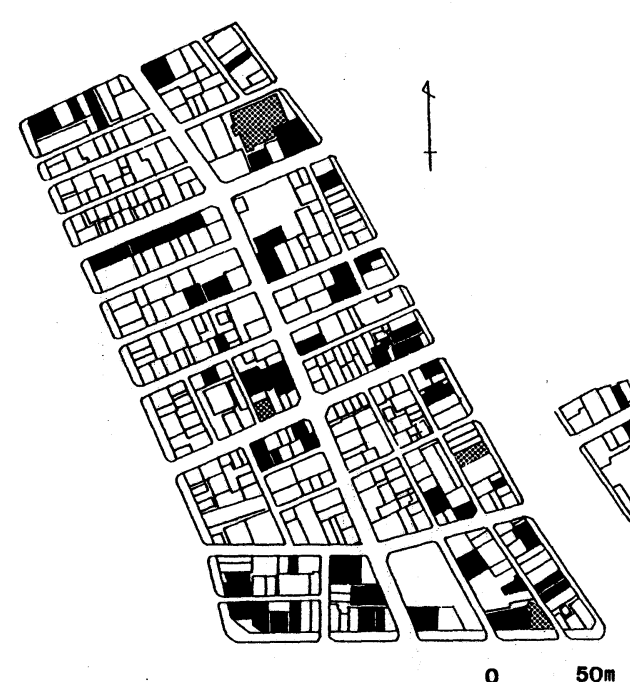

A

a : 1972 


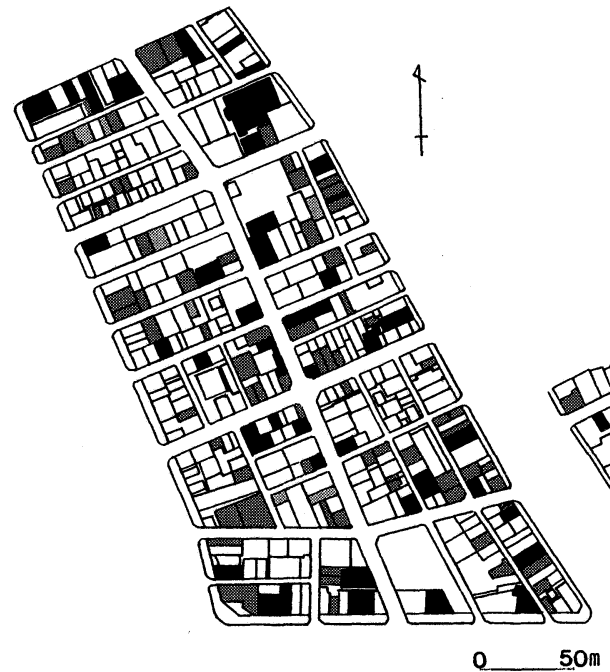

A

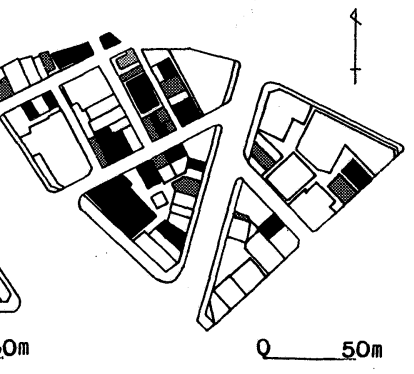

B
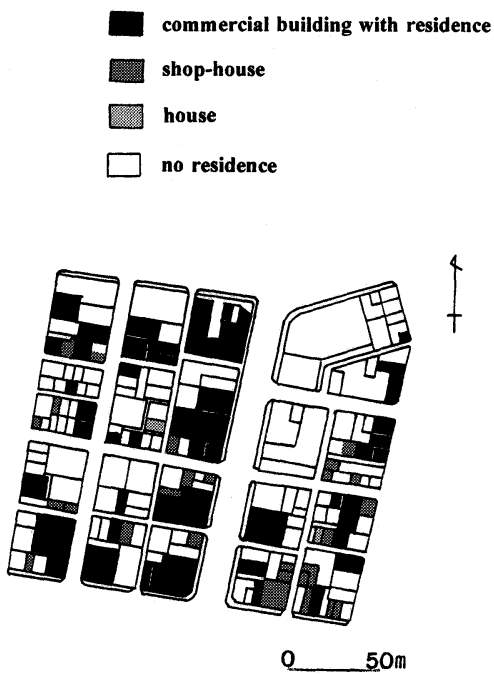

C

Figure 12. Distribution of the residences in three districts, 1988. Source: Author's field survey.

ings was two buildings, located in the west part of Ogawa-cho 3-chome, which were built by the land owners and the inside spaces leased to former renters. One of them housed 12 tenants including three shops with their residences.

This rebuilding process was already under way in the neighborhood of Tsukasa-ichi choukai in 1972. Especially, 70 percent of such buildings were concentrated on the west side of Sotobori street. As of 1988, the author confirmed that about 45 percent of buildings were constructed by local residents or land owners at the individual bases, making this neighborhood most advanced in individual rebuilding processes.

A new banking loan service for individuals at low interest rates, which made it possible for shop and small plant owners to construct commercial buildings, was one of the major pushing factors for this rebuliding phenomenon. After a continuing long high-interest period, the average loan rate of commercial banks in Japan peaked at 8.32 percent in 1980 . Then it began to fall to 6.67 percent in 1984 and to 5.09 percent in 1987.

The main reason for this rebuilding into commercial buildings, performed by the land owners, mostly shop and small plant owners, was to increase their benefits through expansion of spatial capacity. ${ }^{9}$ From around 1985 , there had been some cases of rebuildig as a tax saving strategy in order to respond to increasing fixed property and inheritance tax. But these reasons have been minor. Incidentally, the value of land at a designated spot in Kanda district rose sharply in the late $1980 \mathrm{~s}$, from 7.3 million yen per square meter in 1986 to 13.4 million yen in 1988 , that is, a 184 percent increase.

Figure 12 shows types of residences in three neighborhoods in Kanda district, where landscape transformation has been progressing. There are three types of residences: first, residences built in commercial buildings including owners' shops; second, traditional two-story shop-houses; and third, independent houses.

In North Jimbo-cho 1-chome, shop-house was the major residential type, sharing 58.8 percent of the total households. The residence built in commercial buildings followed with 38.5 percent of households. The author confirmed in the field research five households residing in individual houses with a share of 2.7 percent. In North Ogawa-machi 3-chome, where constructing multi-story buildings was well under way, residence in commerial buildings was the most popular type, sharing 77.5 percent of the total households. Shop-houses had only a 20 percent share and there was only one individ- 
ual house. Since those two neighborhoods had no apartments at the time of field reseacch in 1988 , a population increase there is not easily expected.

Former Tsukasa 1-chome had one apartment building. But it did not have an effect on the existence of choukai. Most residents there (73.4 percent of the total households) lived in a residential space in commercial buildings like those in North Ogawa-machi 3-chome. A type of shop-house followed with a share of 7.1 percent. There were two individual houses. If the households in the apartment mentioned above were included, the share reached 19.5 of the total households.

The facts mentioned above demonstrate that the typical residential type in those neighborhoods has changed from two-storey shop-house to residence built in commercial buildings. They also indicate that the number of residentsturned-commuters was rising in these neighborhoods.

\section{Characteristics of residents and households}

Charateristics of residents will be explored in this section. Figure 13 shows population pyramids of three neighborhoods in 1988. Graph A is the population pyramid of North Jinbo-cho 1chome. Concerning the male population, the age cohort of 20 to 24 years old outnumbered other cohorts, compared to that of the total male population pyramid of Chiyoda ward. This is due to the fact that this disrict housed many male singles living in companys' dormitories and those living in their master's houses. However, since the number of people who wants better living environment has been increasing, along with improvement of living standard, those singles living in the traditional residences are decreasing. On the other hand, the male age cohort over 65 years old had a share of 15.7 percent of the total male population, which was 3.6 percent higher than that of the entire Chiyoda ward. High percentage of aged people has been a distinctive characteristic of Kanda district.

Graph B indicates that in North Ogawa-machi 3-chome, a male age cohort of 10 to 14 years old, which corresponds to the ages of highgraders of elementary school and those of jun-
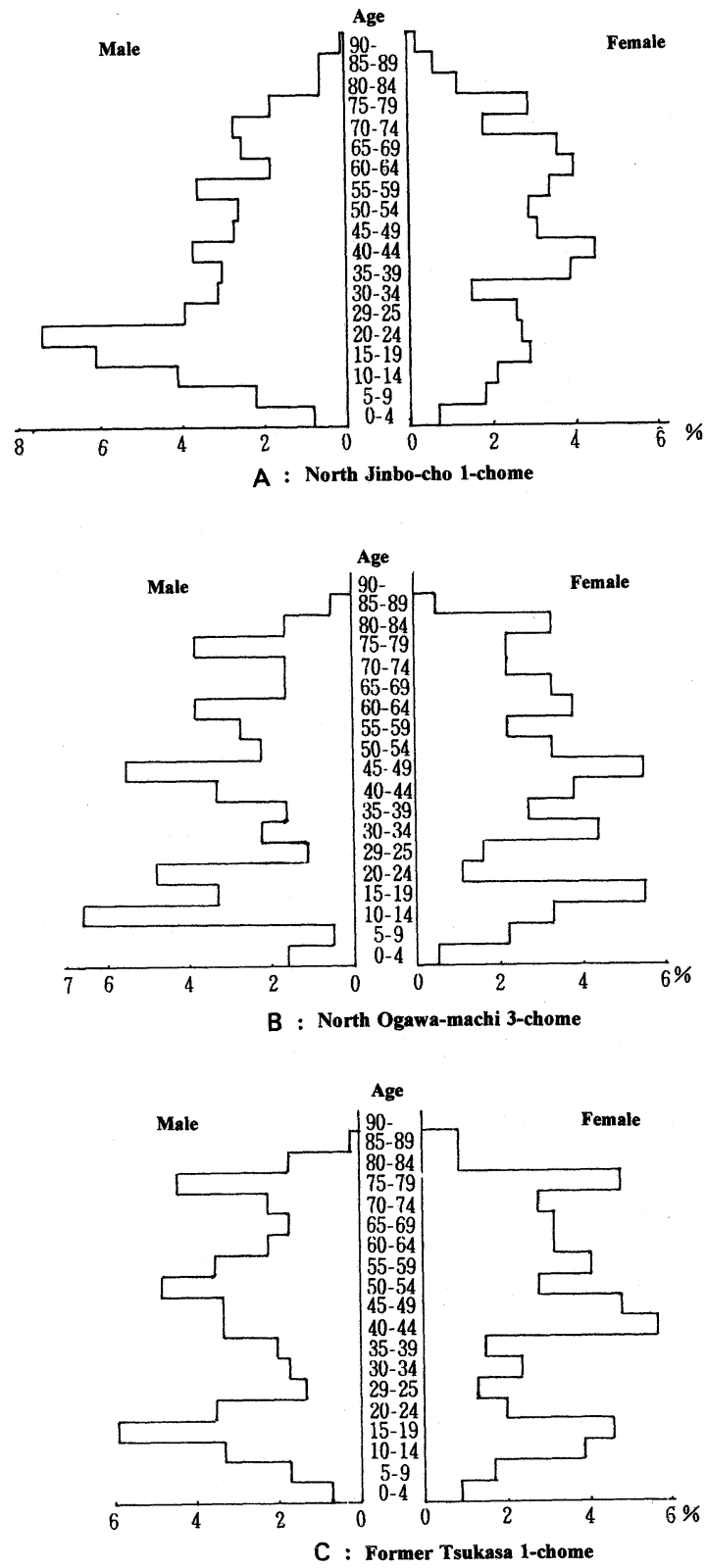

Figure 13. Population pyramids of three districts, 1988.

Source: Registration records of the residents in the ward of Chiyoda.

ior-high school students, shared 6.6 percent of the total male population. In this neighborhood, there was no projection of an age cohort of 20 to 24 years old. This is probably due to the small number of singles like those living in company dormitories. The percentage of male aged over 65 years was 19.5, which was 7.6 



Figure 14. Distribution of inhabitants older than 64 years old in three districts, 1988.

Source: Unpublished document of choukai, registration records of the residents in the ward of Chiyoda, and author's field survey.

percent higher than that of the entire Chiyoda ward. Female population in the age cohort of 10 to 14 years old was also high with a share of 5.5 percent. The percentage of female aged over 65 years reached 22.1 percent of the total female population; that means that approximately one out of five females was over 65 years old. Since the actual number of registered residents was only 182 as of 1988, this analysis might be not appropriate. But at least it would be possible to confirm the tendency of aging processes.

Next, in the graph $\mathrm{C}$ of former Tsukasa 1chome, it is distinctive that the male age cohort of 15 to 19 years old, sharing 5.9 percent of the total male population, outnumbered other cohorts. But the population cohorts above that cohort had much less shares and the age cohort of 25 to 29 years old had only a 1.3 percent share. This change matched the tendency of the entire ward for new graduates to move out the ward when they began to work. The age cohort of 40 to 59 years old had a larger share, around three to four percent. Among aged cohorts, that of 75 to 79 years old had a high share of 4.4 percent of the total. That shows their tendency of preferring to remain in the neighborhood. On the other hand, the female population cohorts up to 39 years old showed a similar outlook to the male cohorts. But the population of 40 to 79 years old was much larger than that of males and the percentage of aged people over 65 years old had a higher share of 24.5 percent of the total female population. That percentage including both sexes reached 23.4 percent, which was 9.1 percent higher than that of the entire Chiyoda ward.

One common characteristic of households among those three neighborhoods as of 1988 was that large households with five or more family members had a share of around 20 percent. When comparing that to the number of family members of the entire Chiyoda ward at the 1984 Census time, the average in the ward was 2.27 persons per household and those of North Jinbo-cho 1-chome, Ogawa-machi 3chome, and former Tsukasa 1-chome were 2.91, 3.20 , and 2.86 , respectively; all of them were above the average of the ward of Chiyoda. This fact makes it possible to assume that the family size in Kanda district would have been generally larger than that in Kojimachi district. Figure 14 shows the distribution of the inhabitants older than 64 yeas old in the three neighborhoods. In the figure, those inhabitants were separated into two groups: households consist- 


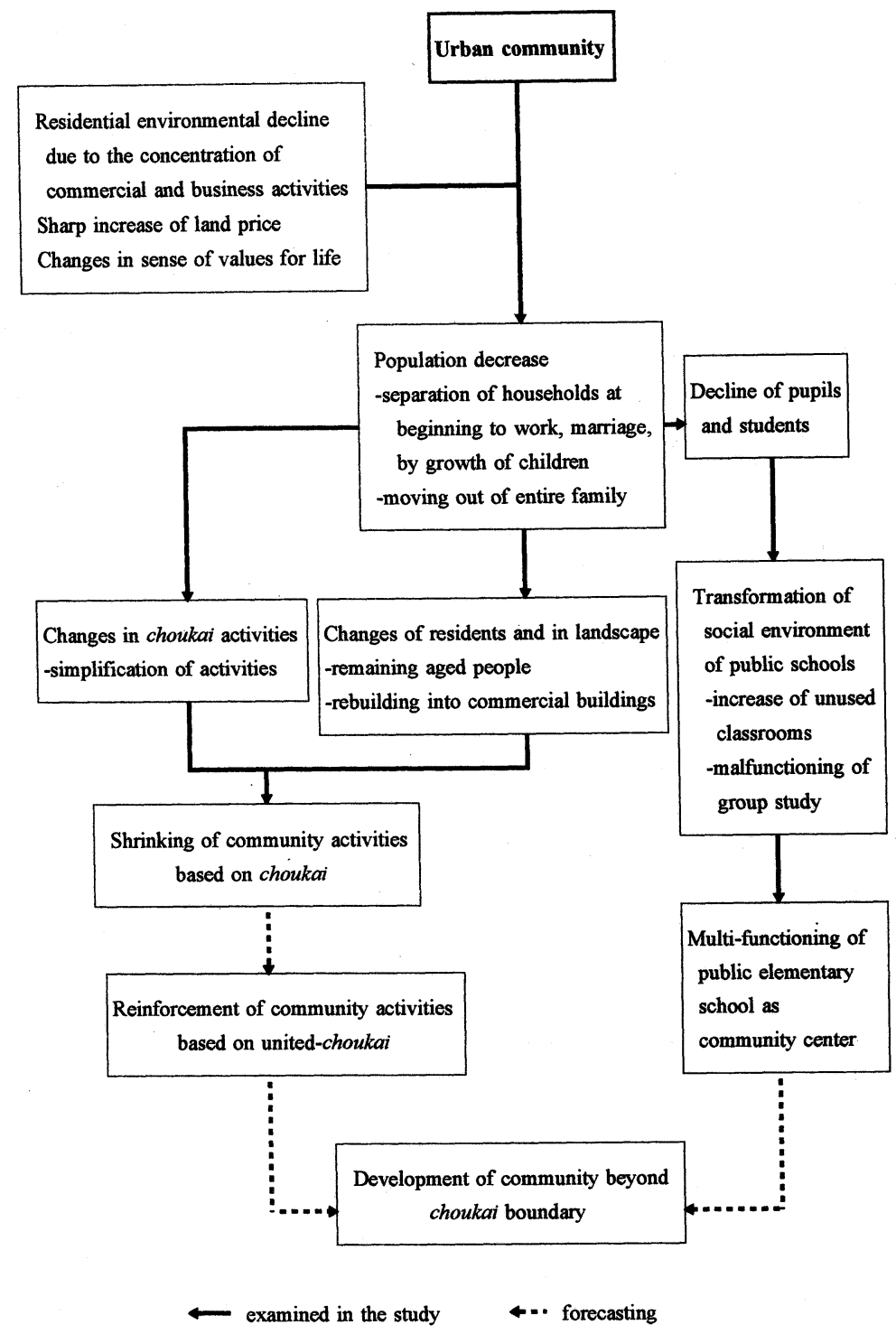

Figure 15. Concept of transformation of community.

ing of aged people only and those consisting of multiple generations. The shares of aged people among households were 43.6 percent in North Ogawa-machi 3-chome, 37.7 percent in North Jimbo-cho 1-chome, and 42.8 percent in the former Tsukasa 1-chome.

In those three neighborhoods, households consisting of aged people only were likely to be found inside each neighborhood. This tendency is also applicable to other households. The author assumes that the portion of the neighborhoods which faces the main streets, experienced rebuilding and remodelling first, along with depopulation and that this process has left the residential pattern mentioned above. Among three neighborhoods examined as examples in Kanada district, former Tsukasa 1-chome, which is next to Otemachi and Marunouchi area, a part of the Central Business District of downtown Tokyo, has advanced most in terms of transformation of landscape and community. 


\section{Conclusions}

This paper aimed to explain transformation of community through depopulation in Kanada district in the ward of Chiyoda, located in central Tokyo. Generally, in the cities in Japan, the basic unit of community corresponds to the territory of chounaikai (choukai in this study), or voluntary association of residents in the neighborhood. In this study the public elementary school district is defined as the higher level unit of community. Major findings of this study are as follows.

The depopulation in the study area has led to the decrease of members of chouaki, which has been the main body of community activities, and it has made it difficult to continue their activities. Increasing aged population due to the out-migration of young residents has resulted in the same situation in the selection of board members of choukai.

Amid choukai activities, which have been performed mainly for developing friendship among its members, the festival for the local shrine has been a particularly important one. Kanda district, which was examined as a field study area, has been divided into two ujiko (worshipers) areas: one of Kanda-myojin shrine and the other of Misaki-shrine. It has become increasingly difficult for both ujiko groups to continue maintainance of their mikoshi (portable shrine) and to get manpower for taking mikoshi around their neighborhoods to the shrine at the festival. As this example demonstrates, it has become clear that curtailment and simplification of choukai activities is gradually under way along with depopulation in the neighborhoods.

With transformation of choukai activities and organization, the change of landscape has also been progressing due to rebuiding and remodelling of traditional shop-houses. This new movement of remodelling into multi-story commercial buildings at an individual level, which started in the 1970s, developed in the 1980s along with the fall of interest rates for loan. This lowered interest rate made it easy for residents and managers of local businesses to raise funds in order to expand space through rebuid- ing. Although one reason for this rebuilding trend might be the jump of the land price in the 1980 s, it is noteworthy that the expansion of vertical space use had been initiated by residents themselves in the neighborhoods well before the rise of the land price. It was reported that real-estate companies were buying up the lands from individual landowners in central Tokyo to construct large commercial buildings. However, it is not the case in the three neighborhoods examined in this study.

The local public school has been one of the most vulnerable institutions among others located in the local community in depopulation. It has been mainly young families who moved out of Kanda district. This has led to a decrease of students at the same time. The reduction in number of students has resulted in an increase of unused class roooms called aki-kyoushitsu, and problems of their effective utilization have surfaced. As one solution, opening of public school facilities to the public is recently progressing. This measure makes it possible to expand the functions of the school from educational only for pupils to community center in the district. As an example, former Sakuma public elementary school was rebuilt into a part of Chiyoda Parkside Plaza, which began to function as a community center for sports and cultural activities, not only for residents in the neighborhoods but also for residents in the entire ward of Chiyoda. Currently, all public elementary schools are superannuated and will be rebulit in the near future, except for two schools which were recently reconstructed. At the same time, it will be necessary to argue whether merger and closure of public elementary schools to the desirable numbers which correspond to the actual number of pupils is needed or not, and to discuss the possibility of converting the school facility to a multi-functional community center. Multi-functioning of Sakuma public elementary school presents a positive example for the future of public educational institutions, which have the strongest tie with the community in the district.

On the other hand, it is assumed that the community based on choukai will be required to solve its problems of uncertainty in foundation of its organization due to depopulation by 
strengthening relations and cooperation with other choukais in adjacent neighborhoods and by shifting the role of main actor to unitedchoukai. At that time, the public elementary school equipped with many facilities can play a role as the center of community activities. The author thinks that it would be possible to stop the current stagnation of community activities based on choukai by changing its central role to united-choukai organized in an elementary school district, which is much larger than the neighborhood scale.

Most previous studies in urban geographhy of Japan have examined inner-city from economic aspects. However, inner-city also has a residential function as well as an economic function. That is one reason for the recent growth of studies of residential functions of inner-city. But it is a future agenda to study everyday-life space which houses a variety of social associations of residents and workers.

Editor's Note: This article was first published in Japanese in the Geographical Review of Japan 63A, 701-721, 1990.

\section{Notes}

1. Also, there is a report published in 1983 by Chiyoda-ku Shakai Kaihatsu Sougou Kenkyusho (General research institute of social development of the ward of Chiyoda). It has examined the mechanism of population decline based on detailed data of the population and land use.

2. In the city of Osaka, where the decrease of the number of pupils also has been serious, the committee for proper locationing of public schools defines the school with less than 200 pupils as kashou-kou (excessively small school).

3. Gakkou jouken kentoukai (Committee of conditions of schools) of the ward of Chiyoda was organized inside its school board in March, 1985 in order to analyse the current situation and desirable conditions of public school education of the ward. The committee presented a report in March 1986, entitled "Decrease of pupils and students and desirable conditions of ward-established public schools." After that the discussion continued with intelligents and the second report, entitled "Change of environmemt surrounding public schools and desirable educational conditions," was published in August 1987.

4. The school board of the Tokyo metropolitan governmnent established a committee to examine the effective use of public school facilities in terms of life-long education in 1987 in order to investigate the present conditions of unused schoolrooms and the possibilities of opening them to the public. The committee is continuing analyses searching for useful examples inside and outside the country.

5. Choukai of North Jimbo-cho 1-chome published a photo book of the neighborhood "Now and Then of North Jimbo-cho 1-chome" by a photographer, Kiyoshi Takahashi, to commemorate the 30th anniversary of its history.

6. Kanda Ogawa-machi, South Jimbo-cho 1chome and Kanda Nishiki-machi have been also a part of ujiko area of Otahime shrine, which was built to pray for Otahime's recovery from illness. Otahime was a daughter of Ota Doukan, who built Edo castle in 1457. Although, currently, Otahime shrine is located in Ogawa-cho 3-chome, it was originally on the bank of Kanda River before the opening of Koubu Railway, which is the present Chuou line of East Japan Railways. Also, in Kanda district is located Yanagimori shrine, which deifies Ubusuna-gami, or guardian god of the locality (Hayashi 1987).

7. Kanda-myojin shrine deifies Taira-no-Masakado, a head of a samurai group which was rooted in Kantou region in the tenth century. The festival of that shrine, together with that of Hie shrine, is called Tenka matsuri ("world" festival), which began in the Edo period.

8. The number of users of ward-established public halls, welfare facilities, and sports centers was 466,217 together in 1985 and 463,635 in 1987, showing a slight decline of users of 0.6 precent.

9. In some neighborhoods in the ward of Chiyoda, in which redevelopment plan has been considered on the choukai basis, it is getting difficult to rebuild personal residences and shops on individual basis. This measure has caused a new problem in neighborhood because families facing the payment of inheritance tax are not able to begin remodelling of their residences and shops with loans as a countermove for paying that tax (if an heir or an heiress has a loan for the residence at the time of inheritance, the inheritance tax is reduced).

\section{References}

Bondi, L. 1987. School closures and local politics: The negotiation of primary school rationalization in Manchester. Political Geography Quarterly 6(3): 203-224.

Chiyoda-ku Shakaikaihatsu Sougoukenkyusho. 1983. Chiyoda-ku jinkou doukou chousa (Report on popu- 
lation dynamics in the ward of Chiyoda). Tokyo: Chiyoda-ku. $(\mathrm{J})$

Fujita H. 1980. Nihon toshi no shakaiteki tokushitsu ni kansuru ichi kousatsu (A study on social characteristics of cities in Japan). Shakaigaku Hyouron (Sociological Review of Japan) 30(4): 2-16. (J)

Hayashi J. 1987. Toukyou Rojou Saiken (A detailed field trip of downtown Tokyo). Tokyo: Heibonsha. $(\mathrm{J})$

Kagawa T. 1984. Toshinbu niokeru minkan shuugou juutaku no ricchi (Locational dynamics of private apartments in downtown). Human Geography 36: 362-375. (JE)

Kagawa T. 1988. Changes within the surronding area of $\mathrm{CBD}$ as affected by the construction of condominiums: A case study of Osaka Ciy. Geographical Review of Japan 61A: 350-368. (JE)

Kashiwabara T. 1980. Daitoshi ni okeru komyunitii zukuri no genjou to kadai (The present conditions and questions of organizing community in large cities). Toshimondai Kenkyuu 32(3): 82-93. $(\mathrm{J})$

Kurata W. 1980. Toshin no kasoka to komyunitii no shomondai (Depopulation in downtown of cities and questions of its community). Toshimondai Kenkyuu 32(3): 51-69. (J)

MacIver, R. M. 1917. Community: A sociological study. London: Macmillan \& Co.

Murphy, R. E., and Vance, J. E. 1954. Delimiting the CBD. Economic Geography 30: 189-212.

Nishida H. 1986. The changes of elementary school districts after closed in the Yoshino Mountainous Area. Human Geography 38: 531-543.

Thomas, R., and Robson, B. 1984. The impact of falling school-roles on the assignment of primary school children to secondary schools in Manchester, 1980-1985. Environment and Planning A 16: $339-356$

Yamamoto N. 1977. Toshin chiku niokeru kasogenshou to gyouseijou no shomondai (Depopulation in downtown of cities and questions of administration). Toshimondai Kenkyuu 29(7): 2-17. (J)

$(\mathrm{J})$ : written in Japanese

(JE): written in Japanese with English abstract 